\title{
PENGARUH KEPEMIMPINAN DAN DISIPLIN KERJA TERHADAP KINERJA KARYAWAN HOKBEN CITRA GARDEN JAKARTA BARAT
}

\author{
${ }^{1 *}$ Chotamul Fajri, ${ }^{2}$ Fikry Dharmawan \\ Universitas Pamulang, Tangerang Selatan, Banten, Indonesia \\ *dosen01717@unpam.ac.id
}

\begin{abstract}
Abstrak
Tujuan dari penelitian ini adalah untuk mengetahui pengaruh kepemimpinan terhadap kinerja karyawan, disiplin kerja terhadap kinerja karyawan serta untuk mengetahui pengaruh antara kepemimpinan dan disiplin kerja secara simultan terhadap kinerja karyawan pada HokBen Citra Garden Jakarta Barat. Metode penelitian yang digunakan dalam penelitian ini adalah Deskriptif Asosiatif dengan pendekatan kuantitatif, yaitu dengan mendeskripsikan keadaan responden serta deskripsi variabel penelitian dalam tabel frekuensi dan presentase dari hasil penyebaran kuesioner tersebut dengan melalui prosedur analisis data. Populasi dalam penelitian ini sebanyak menggunakan sampel jenuh. Teknik analisis data menggunakan uji validitas, uji reliabilitas, uji signifikansi $t$, uji signifikansi f, koefisien korelasi dan koefisien determinasi. Hasil penelitian dapat disimpulkan bahwa variabel kepemimpinan dan disiplin kerja berpengaruh secara positif dan signifikan secara simultan terhadap kinerja karyawan HokBen Citra Garden. Koefisien determinasinya sebesar 0,533 yang artinya kinerja karyawan sebesar 53,3\% dapat dijelaskan oleh variabel kepemimpinan dan disiplin kerja dan sisanya dapat dijelaskan di penelitian lain.
\end{abstract}

Kata Kunci: Kepemimpinan, Disiplin Kerja, Kinerja

\section{Abstract}

The purpose of this study was to determine the effect of leadership on employee performance, work discipline on employee performance and to determine the effect of leadership and work discipline simultaneously on employee performance at HokBen Citra Garden, West Jakarta. The research method used in this research is descriptive associative with a quantitative approach, namely by describing the condition of the respondents and the description of the research variables in the frequency and percentage tables from the results of distributing the questionnaires through data analysis procedures. The population in this study as much as using a saturated sample. The data analysis technique used validity test, reliability test, $t$ significance test, $f$ significance test, correlation coefficient and coefficient of determination. The results of the study can be concluded that the variables of leadership and work discipline have a positive and significant effect simultaneously on the performance of HokBen Citra Garden employees. The coefficient of determination is 0.533 , which means that $53.3 \%$ of employee performance can be explained by the variables of leadership and work discipline and the rest can be explained in other studies.

Keywords: Leadership, Work Discipline, Performance

\section{PENDAHULUAN}

Sumber Daya Manusia adalah salah satu faktor yang sangat penting bahkan tidak dapat dilepaskan dari sebuah organisasi, baik institusi maupun perusahaan. Sumber Daya Manusia juga merupakan kunci yang menentukan perkembangan perusahaan. Pada hakikatnya, Sumber Daya Manusia berupa manusia yang dipekerjakan di sebuah organisasi sebagai penggerak, pemikir dan perencana untuk mencapai tujuan organisasi itu. Sumber Daya Manusia merupakan faktor yang sangat menentukan dalam menjalankan aktifitas organisasi guna mencapai tujuan yang diinginkan. Karyawan merupakan sumber daya penting dalam keberhasilan suatu organisasi, karena kegagalan seorang pegawai dalam melaksanakan tugas dan tanggung jawabnya akan mempengaruhi proses pencapaian tujuan yang telah ditetapkan organisasi. Hal ini menjadi suatu masalah yang cukup rumit, sehingga 
organisasi mengalami kesulitan dalam menetapkan kebijakan terutama yang berhubungan dengan Sumber Daya Manusia, yang merupakan perangkat utama atas kelancaran aktivitas suatu organisasi.

HokBen merupakan restoran yang menyajikan makanan jepang dan sudah berdiri dari tahun 1985 sampai dengan saat ini. HokBen atau dahulu bernama Hoka Hoka Bento sukses bertahan hingga lintas generasi. HokBen biasa menyediakan makanan jepang cepat saji yang sekarang sudah mempunyai banyak menu. Jika anda pergi kesana, anda akan merasakan makan dengan sensasi seperti di Jepang, karena restaurant ini memang mempunyai tampilan yang mirip dengan restaurant yang ada di Jepang sana. Disiplin, kreativitas, serta dedikasi yang tinggi dari para karyawannya sampai saat ini menjadikan Hokben sebagai salah satu restoran yang sudah banyak dikenal diseluruh Indonesia. Lalu pengaruh kepemimpinan di HokBen juga sangat penting bagi kinerja karyawannya dan juga target yang akan dicapai, karena kepemimpinan adalah kemampuan yang terdapat di dalam diri seseorang untuk bisa memengaruhi orang lain atau memandu pihak tertentu untuk mencapai tujuan dan seni seorang pemimpin yaitu mempengaruhi perilaku bawahan, agar mau bekerja sama dan bekerja secara produktif untuk mencapai tujuan organisasi. Sedangkan masalah yang ada didalam HokBen Citra Garden Jakarta Barat yaitu sikap pemimpin yang kurang menghargai hasil kerja karyawan, kurangnya motivasi yang diberikan oleh atasan/ pemimpin terhadap karyawannya, dan pemimpin yang terburu - buru dalam mengambil keputusan sehingga ini akan berpengaruh juga terhadap kinerja karyawan di HokBen Citra Garden Jakarta Barat. Maka dari itu perlu adanya optimalisasi kembali dalam rangka meningkatkan kepemimpinan di Hokben Citra Garden . Berikut adalah data karyawan yang berada di HokBen Citra Garden Jakarta Barat :

Tabel 1. Jumlah Data Karyawan HokBen Citra Garden Jakarta Barat Tahun 2019

\begin{tabular}{|c|c|c|}
\hline No. & Jabatan & Jumlah \\
\hline $\mathbf{1 .}$ & Store Manager & 1 \\
\hline $\mathbf{2 .}$ & Store Supervisor & 5 \\
\hline $\mathbf{3 .}$ & Jr. Store Supervisor & 3 \\
\hline $\mathbf{4 .}$ & Star Crew & 14 \\
\hline $\mathbf{5 .}$ & Crew & 10 \\
\hline $\mathbf{6 .}$ & Delivery & 7 \\
\hline \multicolumn{2}{|c|}{ Jumlah } & 40 \\
\hline
\end{tabular}

Sumber : HokBen Citra Garden Jakarta Barat

Disiplin kerja merupakan salah satu faktor yang dapat mempengaruhi kinerja pegawai. Kurangnya kedisiplinan dan tidak taatnya pada peraturan dan norma-norma yang berlaku maka akan berpengaruh terhadap efektifitas dan efisiensi kerja. Salah satu permasalahan mengenai kedisiplinan yang ada di lingkungan HokBen Citra Garden yaitu masih banyaknya karyawan yang tidak masuk karena izin atau tanpa alasan dan meningkatnya keterlambatan karyawan dalam kurun waktu 2 tahun terakhir. Berikut adalah data absensi karyawan dari tahun 2018 sampai dengan tahun 2019.

Tabel 2. Data Absensi Karyawan HokBen Citra Raya Jakarta Barat Tahun 2018 - 2019

\begin{tabular}{|c|c|c|c|c|c|c|c|}
\hline \multirow{2}{*}{ No. } & \multirow{2}{*}{ Bulan } & \multicolumn{4}{|c|}{$\mathbf{2 0 1 8}$} & \multicolumn{3}{|c|}{$\mathbf{2 0 1 9}$} \\
\cline { 3 - 8 } & & $\begin{array}{c}\text { Alpa } \\
\text { (Orang) }\end{array}$ & $\begin{array}{c}\text { Izin } \\
\text { (Orang) }\end{array}$ & $\begin{array}{c}\text { Telat } \\
\text { (Orang) }\end{array}$ & $\begin{array}{c}\text { Alpa } \\
\text { (Orang) }\end{array}$ & $\begin{array}{c}\text { Izin } \\
\text { (Orang) }\end{array}$ & $\begin{array}{c}\text { Telat } \\
\text { (Orang }\end{array}$ \\
\hline $\mathbf{1}$ & Januari & 0 & 1 & 2 & 2 & 0 & 1 \\
\hline $\mathbf{2}$ & Februari & 1 & 1 & 1 & 3 & 2 & 3 \\
\hline $\mathbf{3}$ & Maret & 1 & 0 & 3 & 1 & 1 & 0 \\
\hline $\mathbf{4}$ & April & 0 & 2 & 1 & 1 & 0 & 0 \\
\hline $\mathbf{5}$ & Mei & 0 & 1 & 1 & 2 & 0 & 3 \\
\hline $\mathbf{6}$ & Juni & 1 & 3 & 2 & 0 & 4 & 2 \\
\hline $\mathbf{7}$ & Juli & 2 & 0 & 2 & 1 & 2 & 1 \\
\hline $\mathbf{8}$ & Agustus & 1 & 0 & 0 & 0 & 0 & 1 \\
\hline $\mathbf{9}$ & September & 0 & 2 & 1 & 0 & 1 & 2 \\
\hline
\end{tabular}




\begin{tabular}{|c|c|c|c|c|c|c|c|}
\hline \multirow{2}{*}{ No. } & \multirow{2}{*}{ Bulan } & \multicolumn{3}{|c|}{$\mathbf{2 0 1 8}$} & \multicolumn{3}{c|}{$\mathbf{2 0 1 9}$} \\
\cline { 3 - 8 } & $\begin{array}{c}\text { Alpa } \\
\text { (Orang) }\end{array}$ & $\begin{array}{c}\text { Izin } \\
\text { (Orang) }\end{array}$ & $\begin{array}{c}\text { Telat } \\
\text { (Orang) }\end{array}$ & $\begin{array}{c}\text { Alpa } \\
\text { (Orang) }\end{array}$ & $\begin{array}{c}\text { Izin } \\
\text { (Orang) }\end{array}$ & $\begin{array}{c}\text { Telat } \\
\text { (Orang }\end{array}$ \\
\hline $\mathbf{1 0}$ & Oktober & 1 & 1 & 2 & 2 & 1 & 0 \\
\hline $\mathbf{1 1}$ & November & 0 & 0 & 0 & 1 & 2 & 0 \\
\hline $\mathbf{1 2}$ & Desember & 2 & 2 & 0 & 1 & 0 & 0 \\
\hline \multicolumn{2}{|c|}{ Total } & 9 & 13 & 16 & 12 & 16 & 10 \\
\hline
\end{tabular}

Sumber : Tim Manajemen Hokben Citra Garden

Berdasarkan tabel 2 dapat dilihat bahwa ketidakhadiran karyawan dan keterlambatan karyawan tidak stabil. Dapat dilihat dari fluktasi absensi selama 2 tahun, Jika kedepannya ketidakhadiran dan keterlambatan karyawan masih terus meningkat, maka dengan demikian kedisiplinan karyawan masih kurang baik. Kehadiran karyawan menjadi hal yang sangat penting karena ketidakhadiran dapat menyebabkan pekerjaan atau tugas

tugas menjadi terbengkalai. Kehadiran karyawan merupakan sikap dari rendahnya kedisiplinan yang dapat menurunkan kinerja karyawan. Menurunnya kinerja karyawan akan menyebabkan perusahaan menjadi lambat dalam mengerjakan sesuatu atau mencapai sebuah tujuan. Maka dari itu hal tersebut harus diperbaiki agar masalah kedisiplinan tidak menimbulkan masalah lainnya.

Tabel 3. Data Penliaian Kinerja Karyawan Hokben Citra Raya Jakarta Barat Tahun 2018 - 2019

\begin{tabular}{|c|c|c|c|c|c|c|}
\hline \multirow[b]{2}{*}{ Tahun } & \multicolumn{4}{|c|}{ Aspek Penilaian } & \multirow[b]{2}{*}{$\begin{array}{c}\text { Rata - } \\
\text { rata }\end{array}$} & \multirow[b]{2}{*}{ Kriteria } \\
\hline & $\begin{array}{c}\text { Kualitas } \\
\text { pelayanan }\end{array}$ & $\begin{array}{c}\text { Target } \\
\text { Penjualan }\end{array}$ & $\begin{array}{c}\text { Kecepatan } \\
\text { bekerja }\end{array}$ & $\begin{array}{l}\text { Tanggung jawab } \\
\text { terhadap pekerjaan }\end{array}$ & & \\
\hline 2018 & 80 & 90 & 70 & 70 & 77,5 & Baik \\
\hline 2019 & 75 & 80 & 65 & 70 & 72,5 & Cukup \\
\hline
\end{tabular}

Sumber : Tim Manajemen Hokben Citra Garden Jakarta Barat

Dengan melihat tabel kinerja karyawan Hokben Citra Garden Jakarta Barat, maka disimpulkan bahwa terdapat kinerja yang kurang optimal dari para karyawannya sehingga nilai rata - rata yang diperoleh menurun. Ini menandakan kinerja karyawan kurang optimal dalam melaksanakan pekerjaannya. Tercapainya tujuan suatu perusahaan juga dipengaruhi dari pegawai yang mempunyai kinerja yang bagus. Hokben Citra Garden Jakarta Barat selalu berusaha untuk meningkatkan kemampuan maupun kinerja karyawan yang dimiliki dengan harapan agar tujuan yang diinginkan dapat tercapai. Selain itu karyawan yang mempunyai kinerja yang bagus akan memberikan pengaruh positif ke dalam maupun ke luar bagi perusahaan. Pengaruh - pengaruh tersebut bisa menjadikan perusahaan mendapatkan value yang lebih dimata masyarakat atau pun pihak yang mempunyai kepentingan.

Ada yang tidak optimal dalam menjalankan tugas pekerjaannya, dan kurang disiplin waktu. Hal inilah yang perlu mendapatkan perhatian dari pihak

manajerial terutama pimpinan perusahaan, agar dapat sedini mungkin mencegah dan berupaya meningkatkan kualitas manajemen sumber daya yang ada pada perusahaan tersebut. Sesuai visi yang digunakan oleh HokBen yaitu "Membawa kebaikan untuk memelihara kehidupan masyarakat dengan menciptakan dan menyediakan makanan yang berintegritas."

Berdasarkan uraian di atas, maka penulis tertarik melakukan penelitian denganjudul: "Pengaruh Kepemimpinan dan Disiplin Kerja Terhadap Kinerja Karyawan Hokben Citra Garden Jakarta Barat".

\section{TINJAUAN PUSTAKA}

\section{Kepemimpinan}

Yang dimaksud kepemimpinan dalam penelitian ini mengacu pada pendapat Sudaryono (2017:8) yaitu "Kepemimpinan adalah setiap perbuatan yang ditentukan oleh individu atau kelompok untuk mengkoordinasi dan memberi arah kepada individu atau kelompok yang 
tergabung didalam wadah tertentu untuk mencapai tujuan yang telah ditetapkan sebelumnya ". Adapun indikator yang digunakan meliputi: 1) Memberikan perintah dan bimbingan, 2) Memberikan arahan, 3) Menumbuhkan inisiatif, 4) Menumbuhkan komunikasi, 5) Mendorong kerjasama.

\section{Disiplin Kerja}

\section{Menurut}

(2015:305) mengemukakan bahwa "Disiplin karyawan dalam manajemen sumber daya manusia berangkat dari pandangan bahwa tidak ada manusia yang sempurna, lepas dari kesalahan dan kekhilafan". Menurut Rivai (2015:825) "Disiplin kerja adalah suatu alat yang digunakan para manajer untuk berkomunikasi dengan karyawan agar mereka bersedia untuk mengubah suatu perilaku dan untuk meningkatkan kesadaran juga kesediaan seseorang agar mentaati semua peraturan dan norma sosial yang berlaku di suatu perusahaan".

3. Kinerja Karyawan

Menurut Wibowo

(2016:18)

mengemukakan "Kinerja merupakan hasil pekerjaan yang mempunyai hubungan kuat strategis organisasi, kepuasan kenosumen dan memberikan kontribusi ekonomi". Sedangkan menurut Ratundo dan Sacket (2012:76) mendefinisikan "Kinerja adalah kegiatan yang mencakup semua tindakan atau perilaku yang dikontrol oleh individu dan memberi kontribusi pada pencapaian tujuan-tujuan perusahaan".

\section{METODE}

Dalam penelitian ini yang menjadi populasi penelitian adalah seluruh karyawan HokBen Citra Garden yang berjumlah 40 orang. Dalam penelitian ini metode yang digunakan dalam penelitian ini adalah sampling sensus atau sampling jenuh, yakni keseluruhan populasi digunakan sebagai sampel dan penelitian, dikarenakan keterbatasan populasi yang ada atau penelitian ingin membuat hasil generalisasi dengan kesalahan yang kecil Sugiyono (2017:85). Adapun sampel yang ditetapkan oleh penulis adalah 40 responden.

Jenis penelitian yang dipakai adalah kuantitatif, dimana tujuannya adalah untuk mengetahui pengaruh antara variabel bebas terhadap variabel terikat baik parsial maupun simultan Dalam menganalisis data digunakan uji instrumen, uji asumsi klasik, regresi, koefisien korelasi, koefisien determinasi dan uji hipotesis.

\section{HASIL DAN PEMBAHASAN}

\section{Pengaruh Kepemimpinan}

Terhadap Kinerja Karyawan (Y)

Berdasarkan hasil analisis, kepemimpinan berpengaruh secara positif dan signifikan terhadap kinerja, hal ini terlihat dari koefisien korelasi sebesar 0,542 yang artinya kedua variabel memiliki tingkat hubungan yang sedang. Uji hipotesis diperoleh nilai thitung (2.786) lebih besar dibandingkan $\mathrm{t}$ tabel (2.026). Dengan demikian $\mathrm{H} 0$ ditolak dan $\mathrm{H} 1$ diterima artinya terdapat pengaruh yang signifikan antara kepemimpinan terhadap kinerja karyawan HokBen Citra Garden Jakarta Barat.

2. Pengaruh Disiplin Kerja (X2) Terhadap Kinerja Karyawan (Y)

Berdasarkan hasil analisis, disiplin kerja berpengaruh secara positif dan signifikan terhadap kinerja, hal ini terlihat dari koefisien korelasi sebesar 0,659 yang artinya kedua variabel memiliki tingkat hubungan yang kuat. Uji hipotesis diperoleh nilai signifikansi t hitung (4.342) lebih besar dibandingkan t-tabel (2.026). Dengan demikian H0 ditolak dan $\mathrm{H} 2$ diterima artinya terdapat pengaruh yang signifikan antara disiplin kerja terhadap kinerja karyawan HokBen Citra Garden Jakarta Barat.

3. Pengaruh Disiplin kerja dan Motivasi Terhadap Kinerja Karyawan

Berdasarkan hasil analisis, Kepemimpinan dan disiplin kerja berpengaruh signifikan terhadap kinerja karyawan dengan persamaan regresi $Y=$ 
7,496+0,228X1+0,606X2. Hal ini dibuktikan dengan nilai korelasi sebesar 0,730 yang artinya variabel bebas dengan variabel terikat mempunyai tingkat hubungan yang kuat dengan koefisien determinasi sebesar 53,3\% sedangkan sisanya sebesar $46,7 \%$ dapat dijelaskan di penelitian yang lain. Uji hipotesis diperoleh nilai $\mathrm{F}$ hitung $>\mathrm{F}$ tabel atau $(21,073>3,24)$. Dengan demikian H0 ditolak dan H3 diterima. Artinya terdapat pengaruh signifikan secara simultan antara kepemimpinan dan disiplin kerja terhadap kinerja karyawan HokBen Citra Garden Jakarta Barat.

\section{PENUTUP}

\section{Kesimpulan}

Berdasarkan dan hasil penelitian dan pembahasan yang telah dilakukan maka diambil kesimpulan sebagai berikut :

1. Kepemimpinan berpengaruh secara positif dan signifikan terhadap kinerja, hal ini terlihat dari koefisien korelasi sebesar 0,542 yang artinya kedua variabel memiliki tingkat hubungan yang sedang. Uji hipotesis diperoleh nilai t hitung (2.786) lebih besar dibandingkan $\mathrm{t}$ tabel (2.026). Dengan demikian HO ditolak dan $\mathrm{H} 1$ diterima artinya terdapat pengaruh yang signifikan antara kepemimpinan terhadap kinerja karyawan.

2. Disiplin kerja berpengaruh secara positif dan signifikan terhadap kinerja, hal ini terlihat dari koefisien korelasi sebesar 0,659 yang artinya kedua variabel memiliki tingkat hubungan yang kuat. Uji hipotesis diperoleh nilai $t$ hitung (4.342) lebih besar dibandingkan t-tabel (2.026). Dengan demikian H0 ditolak dan $\mathrm{H} 2$ diterima artinya terdapat pengaruh yang signifikan antara disiplin kerja terhadap kinerja karyawan.

3. Kepemimpinan dan disiplin kerja berpengaruh signifikan terhadap kinerja karyawan dengan persamaan regresi $Y=$ $7,496+0,228 \times 1+0,606 \times 2$. Hal ini dibuktikan dengan nilai korelasi sebesar 0,730 yang artinya variabel bebas dengan variabel terikat mempunyai tingkat hubungan yang kuat dengan koefisien determinasi sebesar 53,3\% sedangkan sisanya sebesar $46,7 \%$ dapat dijelaskan di penelitian yang lain. Uji hipotesis diperoleh nilai $\mathrm{F}$ hitung $>\mathrm{F}$ tabel atau (21.073 > 3.240). Dengan demikian H0 ditolak dan H3 diterima. Artinya terdapat pengaruh signifikan secara simultan antara kepemimpinan dan disiplin kerja terhadap kinerja karyawan.

\section{Saran}

Berdasarkan hasil penelitian dan pembahasan maka dapat diberikan saran sebagai berikut :

1. Bagi Perusahaan

a. Untuk variabel kepemimpinan, berdasarkan hasil deskripsi jawaban responden dapat dilihat dari nilai rata - rata terendah yaitu ada pada indikator KP2 dengan nilai 3,85 yang berisi pernyataan "Kurangnya pemimpin memberikan motivasi". Oleh karena itu saran untuk manajemen perusahaan dalam meningkatkan kinerja karyawan sebaiknya pimpinan didalam perusahaan lebih menghargai hasil kinerja karyawan, serta memberikan motivasi kepada karyawan demi terciptanya kinerja yang baik.

b. Untuk variabel disiplin kerja, berdasarkan hasil deskripsi jawaban responden dapat dilihat dari nilai rata - rata terendah yaitu ada pada indikator DK7 dengan nilai 3,45 yang berisi pernyataan "Perusahaan tidak memberikan apresiasi bagi karyawan yang tingkat kehadirannya baik". Oleh karena itu saran untuk manajemen perusahaan agar dapat memberikan penghargaan kepada karyawan yang mematuhi dan menjalankan aturan dari perusahaan agar kinerja karyawan menjadi lebih baik lagi.

c. Untuk variabel kinerja, berdasarkan hasil deskripsi jawaban responden dapat dilihat dari nilai rata - rata terendah yaitu ada pada indikator KN2 dengan nilai 3,70 yang berisi 
pernyataan "Saya mampu menyelesaikan tugas pekerjaan dalam mencapai tujuan yang ditetapkan oleh perusahaan". Oleh karena itu saran untuk manajemen perusahaan harus selalu mengingatkan kepada karyawan akan pentingnya kuantitas dan kualitas dalam bekerja, dan pimpinan perusahaan harus selalu melakukan penilaian terhadap kinerja karyawan yang dimana hasilnya akan dijadikan bahan evaluasi agar kinerja karyawan dapat ditingkatkan lebih baik lagi.

2. Bagi Peneliti Selanjutnya

Sehubungan penelitian ini memiliki keterbatasan dalam melakukan penelitian, disarankan agar penelitian selanjutnya dapat mengembangkan variabel - variabel lain seperti beban kerja, stress kerja, serta variabel lainnya yang juga relevan yang memiliki pengaruh terhadap kinerja karyawan.

\section{DAFTAR PUSTAKA}

Chotamul Fajri, H. D. (2020). Pengaruh Disiplin Kerja terhadap Kinerja Karyawan pada CV Permata Mitra Karya Tangerang Selatan. Jurnal Inovasi Bisnis dan Akuntansi, Volume 1 No 2 ( 57-62).

Ghozali, I. (2011). Aplikasi Analisis Multivariate Dengan Program SPSS. Semarang: Badan Penerbit Universitas Diponegoro.

Hermawati, R., Sugiyarti, L., Handayani, R., Sunarsi, D., Alfiah, S., \& Maddinsyah, A. (2020). The Effect of Trilogy Leadership Style and Organization Culture on School Performance: Evidence form Indonesian Senior High School. PalArch's Journal of Archaeology of Egypt/Egyptology, 17(6), 8512-8537.

Indra Marjaya, F. P. (2019). Pengaruh Kepemimpinan, Motivasi, dan Pelatihan terhadap Kinerja Pegawai PDAM Tirta Deli. Jurnal Ilmiah Magister Manajemen, Volume 2 No 1 ( 129-147 ) ISSN 2623-2634.
Insani, P. B. E. B. (2020). Hubungan Gaya Kepemimpinan Dengan Produktivitas Kerja Pegawai Bmt El Bina Insani Cugenang. Jurnal Agrita Vol, 2(1).

Lidia Saputri, A. P. (2017). Pengaruh Gaya Kepemimpinan dan Disiplin Terhadap Kinerja Pegawai Kantor Camat Sagulung. Jurnal Equilibra, ISSN : 2503 - 1546.

Mangkunegara, Anwar Prabu. (2015). Manajemen Sumber Daya Manusia Perusahaan. Bandung : PT. Remaja Rosdakarya

Nurjaya, N., Sunarsi, D., Effendy, A. A., Teriyan, A., \& Gunartin, G. (2021). Pengaruh Etos Kerja Dan Disiplin Kerja Terhadap Kinerja Pegawai Pada Dinas Kehutanan Dan Perkebunan Kota Bogor. JENIUS (Jurnal Ilmiah Manajemen Sumber Daya Manusia), 4(2), 172-184.

Pawar, A., Sudan, K., Satini, S., \& Sunarsi, D. (2020). Organizational Servant Leadership. International Journal of Educational Administration, Management, and Leadership, 63-76.

Sedarmayanti. (2011). Manajemen Sumber Daya Manusia. Bandung: Pustaka Setia.

Siagian, S. P. (2012). Manajemen Sumber Daya Manusia. Jakarta: Bumi Aksara.

Sugiyono. 2012. Statistik Untuk Penelitian. Bandung : Alfabeta

Sunarsi, D. (2014). Pengaruh Gaya Kepemimpinan, Motivasi dan Disiplin Kerja Terhadap Kinerja Pendidik (Doctoral dissertation, Universitas Pamulang).

Wa Ode Zusnita Muizu, U. K. (2019). Pengaruh Kepemimpinan terhadap Kinerja Karyawan Perbankan Sulawesi Tenggara. Jurnal Pendidikan Kewirausahaan Indonesia, Volume 2 No 1 ( 61-78 ) E-ISSN : 2655-5638.

Wastuti, S. N. (1 Mei 2019). Pengaruh Kepemimpinan dan Disipin Kerja terhadap Kinerja Karyawan CV. Sari Arta Medan. Jurnal Psikologi, Vol 2 No 1 e-ISSN : 2598 - 8026. 